\title{
Disinfection of the flexible fibreoptic bronchoscope against Mycobacterium tuberculosis and $M$ gordonae
}

\author{
D DAVIS, HW BONEKAT, D ANDREWS, JW SHIGEOKA
}

From the Departments of Medicine (Pulmonary Section) and Pathology (Laboratory Service), Veterans Administration Medical Center and University of Utah School of Medicine, Salt Lake City, Utah, USA

ABSTRACT In view of recent reports of contamination of the fibreoptic bronchoscope by tuberculous and non-tuberculous mycobacteria, we evaluated the disinfecting properties of aqueous glutaraldehyde (Cidex) and an iodophor (Prepodyne) against Mycobacterium tuberculosis and $M$ gordonae. We found that a 15 minute disinfection procedure with either agent, coupled with initial vigorous mechanical cleaning of the bronchoscope and its accessories, is a quick and reliable method for preventing the contamination of the bronchoscope with mycobacteria.

Although flexible fibreoptic bronchoscopy has become accepted as a safe diagnostic and therapeutic procedure, one of its complications is infection. ${ }^{1-9}$ Recently there have been reports of pulmonary tuberculosis caused by a contaminated bronchoscope. ${ }^{1011}$ There are also reports of contamination by non-tuberculous mycobacteria in specimens obtained through the flexible fibreoptic bronchoscope, ${ }^{1213}$ which may lead to an erroneous diagnosis and inappropriate treatment. Leers ${ }^{10}$ reviewed the procedures for disinfecting flexible fibreoptic bronchoscopes, but there is no consensus about the most reliable and rapid method for disinfecting the fibreoptic bronchoscope against mycobacterial organisms. We therefore set out to determine whether glutaraldehyde and iodophor, when used in the manner recommended by one fibreoptic bronchoscope manufacturer (Olympus), will disinfect a substantial inoculum of Mycobacterium tuberculosis and $M$ gordonae.

\section{Methods}

The bronchoscope (Model B1T, Olympus) was contaminated on 12 different occasions: six times with $M$ gordonae and six times with $M$ tuberculosis. The fibreoptic bronchoscope and accessories were disinfected with either aqueous glutaraldehyde or iodophor and each disinfectant was tested against each organism on three different occasions.

\footnotetext{
Address for reprint requests: Dr HW Bonekat, Pulmonary Section 111B, Veterans Administration Medical Center, 500 Foothill Boulevard, Salt Lake City, Utah, 84148, USA.

Accepted 8 May 1984
}

PREPARATION OF THE INOCULUM

Stock cultures of $M$ gordonae (Trudeau Mycobacterium Culture (TMC) No 1318 strain W911) and $M$ tuberculosis (TMC No 201 and strain H37RA) were grown to turbidity in Dubos medium ${ }^{14}$ and were diluted in $100 \mathrm{ml}$ of sterile $7 \%$ albumin solution. $M$ gordonae is a common contaminant which is non-pathogenic and safe to handle and H37RA is an attenuated strain of $M$ tuberculosis. The $7 \%$ albumin solution was used to simulate the viscous character of bronchial secretions. With the use of a 0.001 calibrated semiquantitative loop, a $7 \mathrm{H}-11$ culture plate was implanted with the inoculating solutions and incubated at $35^{\circ} \mathrm{C}$ in $7 \%$ carbon dioxide until growth appeared. The colonies were counted and the number was multiplied by the dilution factor ( $\times 1000)$. The concentration of organisms was $4 \cdot 2$ $\times 10^{6} \mathrm{M}$ gordonae $/ \mathrm{ml}$ and $3.12 \times 10^{5} \mathrm{M}$ tuberculosis/ml.

\section{SIMULATING CONTAMINATION}

The following pieces of equipment were used in the experiment: (1) the automatic aspiration adaptor, located at the proximal end of the channel sleeve and used to control suction during bronchoscopy; (2) the cleaning brush, used for cleaning the suction channel; (3) the manual suction adaptor, which replaces the automatic aspiration adaptor during cleaning to irrigate the channel; and (4) the distal tip of the fibreoptic bronchoscope and its suction channel.

To contaminate the fibreoptic bronchoscope (which had been gas sterilised with ethylene oxide at twice atmospheric pressure for six hours and 
allowed to aerate for at least 36 hours), the tip was immersed in $100 \mathrm{ml}$ of inoculating solution. The solution was aspirated through the channel into the automatic aspiration adaptor with a syringe and allowed to stand for 15 minutes. The aspirated solution was then discarded, and material for culture was obtained from the various components of the fibreoptic bronchoscope to serve as a positive control. The inoculating process was then repeated. To simulate the clinical setting, in which time may elapse between using and cleaning the fibreoptic bronchoscope, the suction channel was drained by gravity and the instrument was allowed to remain undisturbed for 15 minutes.

\section{DISINFECTION}

The bronchoscope, the automatic aspiration adaptor, and the cleaning brush were all cleaned in a manner similar to that recommended by the manufacturer: the fibreoptic bronchoscope was immersed in sterile water, the suction channel was cleaned by passing the cleaning brush through the bronchoscope five times, and the channel was vigorously irrigated with about $10 \mathrm{ml}$ of sterile water. The automatic aspiration adaptor was disassembled (fig), immersed in sterile water, and mechanically cleaned with the cleaning brush. The cleaning brush was rubbed vigorously between gloved fingers to remove all debris.

The solutions whose ability to kill mycobacteria were studied were (1) a commercially available undiluted iodophor solution containing $1 \%$ titratable iodine (Prepodyne, AMSCO Medical Products Division, Erie, Pennsylvania, and (2) freshly activated $2 \%$ alkaline glutaraldehyde ( $\mathrm{pH}$ 8-8.5, Cidex, Surgikos Inc, Arlington, Texas). The cleaning brush, the distal $40 \mathrm{~cm}$ of the fibreoptic bronchoscope, and the automatic aspiration adaptor were immersed in either glutaraldehyde or iodophor. After 15 minutes of contact with the disinfectant solution all equipment was thoroughly rinsed in sterile water and material was obtained for culture from the fibreoptic bronchoscope, automatic aspiration adaptor, and cleaning brush.

\section{CULTURE TECHNIQUE}

Material was obtained at the following times: (1) before contamination; (2) after immersion in inoculating solution, to demonstrate that contamination had taken place; and (3) after disinfection.

The distal $5 \mathrm{~cm}$ of the fibreoptic bronchoscope was immersed in a $35 \mathrm{ml}$ glass incubation tube containing $20 \mathrm{ml}$ of sterile Dubos medium. The medium was aspirated with a syringe through the suction channel and the manual suction adaptor, allowed five minutes of contact time, and then returned to

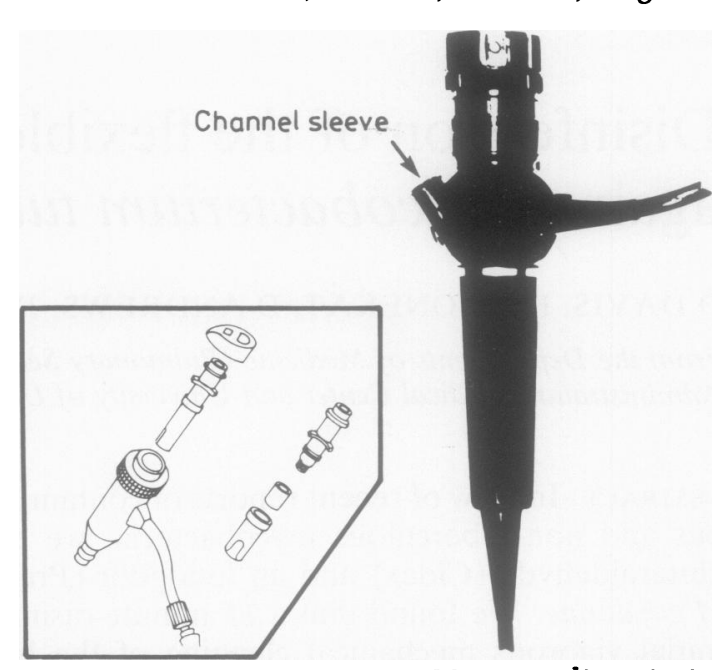

Close up view of the components of the automatic aspiration adaptor that inserts into the channel sleeve during bronchoscopy.

the original glass tube. The automatic aspiration adaptor was disassembled and placed in a specimen cup containing $20 \mathrm{ml}$ of sterile Dubos medium for five minutes. The medium was then transferred to a sterile $35 \mathrm{ml}$ glass incubation tube. The tip of the cleaning brush was immersed in $20 \mathrm{ml}$ of Dubos medium contained in a $35 \mathrm{ml}$ glass tube for five minutes.

Cultures were incubated in $7 \%$ carbon dioxide at $35^{\circ} \mathrm{C}$ for five weeks. Growth was detected by making smears of turbid broths or by centrifuging clear broths at $3000 \mathrm{~g}$ for 15 minutes in $50 \mathrm{ml}$ plastic centrifugation cups and making smears of the sediment. The smears were stained with Auramine $\mathrm{O}-$ Rhodamine $B$ acid fast stain $^{15}$ and examined by fluorescent microscopy. The demonstration of fluorescent bacilli in culture material was interpreted as a "positive" culture and their absence was interpreted as a "negative" culture.

All work was performed under a laminar airflow hood with sterile gloves, masks, and gowns.

\section{Results}

The culture results showed that each component of 0 the equipment (bronchoscope, automatic aspiration $\frac{\bar{\Phi}}{\mathscr{D}}$ adaptor and cleaning brush) was on each occasion $\stackrel{\oplus}{+}$ contaminated after exposure to the inoculating material. After disinfection with either glutaraldehyde $\stackrel{\vec{P}}{\overrightarrow{0}}$ or iodophor, however, the cultures for either $\stackrel{\mathbb{Q}}{\mathcal{Q}}$ $M$ tuberculosis or $M$ gordonae on all pieces of $\frac{\mathbb{\Phi}}{\alpha}$ equipment were on each occasion negative. Thus mechanical cleaning of the fibreoptic bronchoscope 
and automatic aspiration adaptor with the cleaning brush and complete contact with either disinfectant solution for 15 minutes eliminated all mycobacteria.

\section{Discussion}

Controversy still exists about which method of rapid, cold disinfection is most reliable in preventing the transmission of mycobacteria by the fibreoptic bronchoscope. Garcia de Cabo and colleagues ${ }^{16}$ used benzalkonium chloride followed by alcohol to disinfect the bronchoscope against several pathogenic organisms, including $M$ tuberculosis. Reports show, however, that benzalkonium chloride fails to kill $M$ tuberculosis ${ }^{1-19}$ and alcohols are unreliable disinfectants against tubercle bacilli in sputum. ${ }^{20}$ Suratt and coworkers ${ }^{21}$ used a more complex protocol of hexachloröphene, povidone-iodine (Betadine), ethanol, and water. Recent studies, however, have shown that Betadine"1 or hexachlorophene ${ }^{22}$ alone may be inactive against $M$ tuberculosis.

Our study indicates that a simple three step procedure of mechanical cleaning followed by 15 minutes' disinfection with either aqueous glutaraldehyde or iodophor (Prepodyne) and rinsing with sterile water effectively eliminated $M$ tuberculosis and $M$ gordonae from an artificially contaminated fibreoptic bronchoscope. We tried to approximate the clinical conditions under which the bronchoscope is contaminated. Highly concentrated inocula of $M$ tuberculosis and $M$ gordonae were mixed with albumin to simulate bronchial secretions contaminated by these organisms. Since there may be a short delay in practice before disinfecting the bronchoscope, we waited for 15 minutes before starting decontamination. Our results may, however, apply only to disinfection performed shortly after using the bronchoscope, since it is possible that prolonged drying might interfere with cleaning and disinfection. The H37RA strain of $M$ tuberculosis used in this study is attenuated, but we have no reason to suspect that the disinfection procedure would be any less effective against more virulent mycobacteria.

All parts of the fibreoptic bronchoscope should be cleaned mechanically before chemical disinfection and particular attention must be given to the components of the automatic aspiration adaptor (fig), which may retain contaminated material.

The disinfectants most recently recommended by the Olympus Company ${ }^{23}$ are an iodophor (Wescodyne) or glutaraldehyde (Cidex, Glutarex, or Sonacide). The chemical agents and periods of disinfection used in the present study appear to be quite satisfactory. Aqueous alkaline glutaraldehyde is highly mycobactericidal ${ }^{24}$ and does not harm the fibreoptic bronchoscope. ${ }^{25}$ It has a slight odour, and since it may be irritating to the eyes and skin it should be rinsed carefully from the instrument and hands. Iodophors are non-irritating but may stain. ${ }^{26}$ Careful removal by wiping the bronchoscope, particularly the distal viewing tip, with a gauze pad and sterile water can prevent discoloration. Recent information suggests that not all iodophors are equally active against mycobacteria, ${ }^{11}$ so it seems reasonable, until more information is available, to use one which is known to have mycobactericidal activity. "Finally the water used for rinsing the bronchoscope should be sterile, to avoid inadvertent contamination with organisms such as $M$ gordonae, which may be present in tap water. ${ }^{27}$

Pappas $e^{2} a^{28}$ recently reported the apparent failure of glutaraldehyde to disinfect the fibreoptic bronchoscope of $M$ chelonei and Pseudomonas aeruginosa. Two bronchoscopes were found to be damaged and they considered the source of the original contamination was tap water or glutaraldehyde solutions, which allowed colonisation of the puncture sites in the suction channel of the bronchoscope. Tap water is a well known source of contamination $^{29}$ and it is likely that infectious organisms collected in these damaged sites, out of reach of the cleaning brush and disinfectant. $M$ chelonei has been isolated from low $(0.2 \%)$ concentration glutaraldehyde packing solutions ${ }^{30}$; but this does not argue against the use of a much higher concentration (2\%) as a disinfecting agent, which in the present study gave satisfactory results.

This study was supported in part by the Veterans Administration. We thank Mrs Elgenia Rogers for secretarial assistance.

\section{References}

'Anonymous. Fibreoptic infections. Lancet 1980;ii:782-3.

${ }^{2}$ Credle WF, Smiddy JF, Elliott RC. Complications of fiberoptic bronchoscopy. Am Rev Respir Dis 1974; 109:67-72.

${ }^{3}$ Pereira W, Kovnat DM, Khan MA, Iacovino JR, Spivack ML, Snider GL. Fever and pneumonia after flexible fiberoptic bronchoscopy. Am Rev Respir Dis 1975; 112:59-64.

${ }^{4}$ Pereira W, Kovnat DM, Snider GL. A prospective cooperative study of complications following flexible fiberoptic bronchoscopy. Chest 1978;73:813-6.

${ }^{5}$ Beyt BE, King DK, Glew RH. Fatal pneumonitis and septicemia after fiberoptic bronchoscopy. Chest 1977; 72: 105-7.

- Timms RM, Harrell JH. Bacteremia related to fiberoptic bronchoscopy. Am Rev Respir Dis 1975;111:555-7.

${ }^{7}$ Webb SF, Vall-Spinosa A. Outbreak of Serratia marcescens associated with the flexible fiberbronchoscope. Chest 1975;68:703-8. 
${ }^{8}$ Scheidt A. Persistent contamination of the flexible fiberbronchoscope following disinfection in aqueous gluteraldehyde. Chest 1980;78:352-3.

${ }^{9}$ Weinstein HJ, Bone RC, Ruth WE. Contamination of a fiberoptic bronchoscope with a Proteus species. Am Rev Respir Dis 1977;116:541-3.

${ }^{10}$ Leers W. Disinfecting endoscopes: how not to transmit Mycobacterium tuberculosis by bronchoscopy. Can Med Assoc J 1980;123:275-83.

$"$ Nelson KE, Larson PA, Schraufnagel DE, Jackson J. Transmission of tuberculosis by flexible fiberbronchoscopes. Am Rev Respir Dis 1983;127:97-100.

12 Dawson DJ, Armstrong JG, Blacklock ZM. Mycobacterial cross-contamination of bronchoscopy specimens. Am Rev Respir Dis 1982;126:1095-7.

${ }^{13}$ Steere AC, Corrales J, Von Graevenitz A. A cluster of Mycobacterium gordonae isolates from bronchoscopy specimens. Am Rev Respir Dis 1979;120:214-6.

${ }_{14}$ Dubos RJ, Fenner F, Pierce $\mathrm{CH}$. Properties of a culture of BCG grown in liquid media containing Tween 80 and the filtrate of heated serum. Am Rev Tuberc 1950;61:66-76.

15 Strong BE, Kubica GP. Isolation and identification of Mycobacterium tuberculosis-a guide for the level II laboratory. Atlanta, Georgia: US Department of Health and Human Services and Center for Disease Control, 1981.

16 Garcia de Cabo A, Martinez Larriba PL, Checa Pinilla J, Guerra Sanz F. A new method of disinfection of the flexible fibrebronchoscope. Thorax 1978;33:270-2.

${ }^{17}$ Hirsch JG. The resistance of tubercle bacilli to the bactericidal action of benzalkoniium chloride (Zephiran). Am Rev Tuberc 1954;70:312-9.

${ }^{18}$ Wayne LG, Krasnow I, Kidd G. Finding the "hidden positive" in tuberculosis eradication programs. The role of the sensitive trisodium phosphatebenzalkonium (Zephiran) culture technique. Am Rev Respir Dis 1962;86:537-41.

${ }^{19}$ Wright ES, Mundy RA. Studies on disinfection of clini- cal thermometers. II. Oral thermometers from a tuberculosis sanatorium. Appl Microbiol 1961;9:508-10.

${ }^{20}$ Frobisher M, Sommermeyer L. A study of the effect of alcohols on tubercle bacilli and other bacteria in sputum. Am Rev Tuberc 1953;68:419-24.

21 Suratt PM, Gwaltney JM, Sande MA. A rapid method of disinfecting the bronchofiberscope. Am Rev Respir Dis 1976;114:1198-200.

${ }^{22}$ Simmons BP, Hooton TM, Mallison GF. Guidelines for the prevention and control of nosocomial infections. Antiseptics, handwashing, and handwashing facilities. Atlanta, Georgia: US Department of Health and Human Services and Centers for Disease Control, 1981.

${ }^{23}$ Olympus Corporation of America: Cleaning and disinfecting booklet. New Hyde Park, New York: Olympus Corporation, 1982.

${ }^{24}$ Collins FM, Montalbine V. Mycobactericidal activity of glutaraldehyde solutions. J Clin Microbiol 1976;4:408-12.

${ }^{25}$ Stonehill AA, Krop S, Borick PM. Buffered glutaraldehyde - a new chemical sterilizing solution. Am J Hosp Pharm 1963;20:458-65.

${ }^{26}$ Taylor JW, Smith VM, Zacher JL. For effective thermometer disinfection. Nursing Outlook 1966;14:568.

${ }^{27}$ Goslee S, Wolinsky E. Water as a source of potentially pathogenic mycobacteria. Am Rev Respir Dis 1976; 113:287-92.

${ }^{28}$ Pappas SA, Schaaff DM, DiCostanzo MB, King FW, Sharp JT. Contamination of flexible fiberoptic bronchoscopes. Am Rev Respir Dis 1983;127:391-2.

${ }^{29}$ Gangadharam PRJ, Lockhart JA, Awe RJ, Jenkins DE. Mycobacterial contamination through tap water. Am Rev Respir Dis 1976;113:894.

${ }^{30}$ Laskowski LF, Marr JJ, Spernoga JF, et al. Fastidious mycobacteria grown from porcine prosthetic-heartvalve cultures. $N$ Engl J Med 1977;297:101-2. 